\title{
Efficacy of case-based learning as an adjunct to traditional teaching learning methods in Physiology
}

\author{
Sumana Panja ${ }^{1}$, Kaushik Bhowmick ${ }^{2}$, Manika Sadhu $^{3}$
}

\begin{abstract}
Introduction: The present study was undertaken with the objective to assess the efficacy of clinical case history based modular teaching learning method on the performance of undergraduate medical students as an adjunct to the traditional teaching methods in physiology.

Materials and Methods: The present study was performed on first professional MBBS students of two consecutive batches of Nilratan Sircar Medical College, Kolkata. After the first semester examination was taken, a significant deviation in teaching-learning method was employed. No case histories were discussed or introduced to the students of batch 2009-2010, batch 2010-2011 but they had been administered clinical case history based modules. Second semester examination was conducted where $25 \%$ of the questions were based on case histories for both batches while the remaining $75 \%$ of the questions consisted of non-case based items.
\end{abstract}

Results: There had been no significant difference in performance $(p=0.246)$ in the first semester examination between the two batches. However, a significant difference $(p<0.05)$ was observed between the performances of the students of these two batches in case based items with batch 20102011 doing better. More importantly, performance of the students between these two batches differed significantly $(p<0.05)$ in favour of batch $2010-2011$, where the marks obtained by them in non-case based items in the second semester examination was considered.

Discussion: The authors concluded that clinical case based modules, when used as an adjunct to didactic lectures, not only served to enhance students' skill in tackling case based items, but also developed their critical thinking and higher ordered learning such that they became more adept at solving non case based items.

Keywords: case based study, physiology

\section{Introduction}

Physiology is an integral part of the medical curriculum. The relevance of this pre-clinical discipline is emphasized during learning of

\footnotetext{
${ }^{1}$ Assistant Professor, Department of Physiology,

Nilratan Sircar Medical College and Hospital,

Kolkata, West Bengal, India

${ }^{2}$ Associate Professor, Department of Biochemistry,

Malda Medical College and Hospital,

Malda, West Bengal, India

${ }^{3}$ Professor, Post Graduate Institute of

Medical Education and research,

Kolkata, West Bengal, India

Corresponding author:

Dr. Sumana Panja,

BC-39/6, Deshbandhu Nagar

P.O: Deshbandhu Nagar

Baguiati, Kolkata

West Bengal, India

Pin: 700059

Email:drkbhowmick@gmail.com
}

pharmacology, pathology, medicine, anesthesiology and other subjects of the medical curriculum. The importance of physiology lies in understanding the pathophysiology of a disease process and appreciating the physiological basis of management of disease. Great advancements in the fields of molecular biology and genetics sometimes seem to conceal the basic need for systemic understanding of integrated regulatory physiological concepts, which has been increasingly difficult by a reduction in the course duration of undergraduate physiology. To meet the need and outcome based course instruction, restructuring of the physiology syllabus is needed. The Medical Council of India $(\mathrm{MCl})$ is contemplating the introduction of e-learning, m-leaning and simulation in teaching learning procedure which require expensive infrastructure, trained personnel and proper maintenance. 
Secondly, students of physiology, which is a subject of the first year MBBS course as per $\mathrm{MCl}$ curriculum, get only a limited opportunity, or not at all, to go to bedside clinics or encounter real patients. As a result, students frequently loose their interest in the theoretical basis of medicine and this becomes a significant challenge for teachers to keep students interested in the subject. Also, the development of critical thinking skills in college students is a goal for many college instructors in higher education (Garrison, 1992). There is evidence that basic science knowledge learned in the context of clinical cases is actually better comprehended and more easily applied by medical students than basic science knowledge learned in isolation (Patel, 1989; Patel, 1988).

In this scenario, if clinical case history based modules can be introduced in physiology, while teaching the important and useful topics, a better impact on teaching-learning (T-L) procedure may be expected. This simple inexpensive interesting approach may make students understand the statement made by Pavlov (year) that medicine is nothing but a better understanding of physiology (Asratyan, 2001). This approach may be useful in aiding the development of critical thinking skills and offer the opportunity to create leaning activities that promote clinical problem solving skills related to normal and abnormal physiology.

In view of these facts, clinical case history based modules were introduced while teaching some particular topics in physiology to undergraduate medical students of Nilratan Sarkar Medical College, Kolkata, India, in order to help them understand and apply the basic physiological concepts in clinical practice and to motivate students to better learn physiology. This present study was undertaken with the objective to assess the efficacy of clinical case history based modular teaching learning method on the performance of undergraduate medical students as an adjunct to the traditional teaching methods in physiology.

\section{Materials and Methods}

The present study was performed on first professional MBBS students studying at Nilratan Sircar Medical College (NRSMC), Kolkata. Two consecutive batches of students, each batch consisting of 150 students of academic sessions 2009-2010 and 2010-2011 were included. Thus, a total of 300 students were included in the study after informed consent had been obtained from them. The study was approved by the Institutional Ethical Committee of Nilratan Sircar Medical College, Kolkata. As modification in teaching-learning and evaluation methods was an integral part of the present endeavor, a detailed description of the same method followed in physiology for these two consecutive sessions is provided.

\section{Teaching-learning method during first semester:}

Subject matter in physiology was taught in the form of didactic lectures in accordance to $\mathrm{MCl}$ and the university is guidelines (Regulations on Graduate Medical Education 1997, Scheme for First Professional MBBS University Examination in Physiology of the West Bengal University of Health Sciences). First semester examination was conducted on general physiology, neuro-muscular physiology hematology, cardiovascular system, respiratory system and gastrointestinal system. Material in this section was presented to students as outlined in most medical textbooks. The batch was then divided into smaller groups of 15 students each. Tutorial classes were conducted for each of these groups where the above topics were again discussed using the group discussion method. The students were given an opportunity to clarify their doubts. During these tutorial sessions no case histories were discussed or introduced to them.

\section{Evaluation Method during First Semester:}

At the end of the first semester, periodical institutional written assessment examination was conducted. Question was prepared according to the West Bengal Health University question pattern from the topics taught during didactic lectures and later discussed during tutorial periods. Items for the question paper were formulated by the teaching faculty of the department and a question bank was generated. These questions were then peer reviewed before their inclusion in the final question paper. No case based items were included in the first semester for both batches. Evaluation of the answers scripts were performed by the faculty of the department as a part of their regular work schedule. 
Teaching-Learning Method during Second Semester:

During this session the topics included were endocrine physiology, reproductive system, central nervous system, special sense and excretory system. During the didactic lecture period, the materials were presented to students as outlined in most of medical textbooks. The batch was divided into smaller groups of 15 students each. Tutorial classes were conducted for each of these groups where the above topics were again discussed using the group discussion method. At this point,a significant deviation in T-L method was employed in the study. While no case histories were discussed or introduced during these tutorial sessions to the students batch of 2009-2010, each group from batch 20102011 was administered clinical case history based modules comprising of clinical case history with symptoms and laboratory investigation reports followed by questions on the said problems. The case histories were selected from very common clinical problems and were kept as brief and appropriate as possible. The questions on clinical case histories were predominantly critical thinking questions based on some physiological concept. The questions on clinical case histories were predominantly critical thinking questions based on some physiological concept.

Most of the tutorial time was devoted to discussing case histories. The emphases in these discussions were on (1) identification of patients' problems, (2) pathophysiology behind that diagnosis, (3) how to interpret laboratory diagnosis, (4) physiological basis of treatment of that disease. A short introduction to each problem was given by the tutorial teachers. Simultaneously, students were asked to list out (1) their queries, (2) provisional diagnosis, (3) most probable diagnosis, (4) lists of further investigations to prove or disprove their hypothesis. During the tutorials, students were given enough time to study the particular clinical cases related to their curriculum with reference to the accompanying questions. In order to generate more interest about the subject from these case discussions, students were allowed to give their inputs to improve the discussion process. After this stepwise discussion during tutorial period, the cases were summarized by the tutor to ensure complete coverage of the physiological process as well as the pathophysiological basis of disease and the physiological basis of treatment of that given problem. The teaching assignments were allocated by randomly assigning tutors and alternating the assignments. The objective and the scope of discussion were precisely outlined between all tutors in order to avoid discrepancies in the information provided and to ensure continuity in the case presentations.

\section{Evaluation Method during Second Semester:}

At the end of the second semester, periodical institutional written examination was conducted. Question was prepared according to the West Bengal Health University question pattern. The question paper was prepared following an identical protocol as that for the first semester examination. Unlike the first semester examination, $25 \%$ of the questions of the second semester were based on case histories for both batches 2009-2010 and 2010-2011. The remaining $75 \%$ of the questions consisted entirely of non-case based items from the topics taught during the second semester.

Reliability of the corresponding pairs of tests had been predetermined by the Equivalent Test Method (Ananthakrishnan 2000). The corresponding pairs of proposed test instruments had been administered on a preselected cohort of undergraduate medical students $(n=25)$ in their $4^{\text {th }}$ to $6^{\text {th }}$ semester of curriculum to obtain two sets of scores. Correlation coefficients had been determined between these two sets. Only those pairs of test instruments had been finally selected for the study which had a correlation coefficient more than 0.90 .

This method has been described to provide a solution too many of the problems inherent in the test-retest reliability method. Since the two forms of the test are different, a carryover effect is less of a problem. Reactivity effects are also partially controlled; although taking the first test may change responses to the second test. However, it is reasonable to assume that the effect will not be as strong with alternate forms of the test as with two administrations of the same test (Davidshofer, 2005).

\section{Statistical Analysis}

Comparison of data was done in several steps using SPSS 11. Mean and Standard Deviation. (SD) of \% of marks were obtained in the $1^{\text {st }}$ semester batch of 2009-2010 was calculated and compared with that of $1^{\text {st }}$ semester of batch of 2010-2011. Also, the 
mean and SD of \% of marks were obtained in the $2^{\text {nd }}$ semester case based items was calculated and compared between the two batches. Finally, the mean and SD of $\%$ of marks obtained in the $2^{\text {nd }}$ semester non case based items was calculated and compared between the two batches.

\section{Results}

The mean and SD of the \% of marks obtained by students of the batch 2009-2010 and 20102011 are given in Table 1. The comparative data on the significance of difference of mean between these two batches are provided in Table 2. There was no significant difference in performance ( $p=0.246$ ) as reflected by the mean of \% marks obtained in the first semester examination between batch 2009-
$2010(M=60.06, S D=12.70)$ and batch 20102011 ( $M=61.64$, SD = 9.86). However, a significant difference $(p<0.05)$ was observed between the performances of the students of these two batches with regard to mean of \% marks obtained in case based items in the second semester examination $(M=47.77, S D$ $=10.07$ for batch $2009-10$ versus $M=60.35$, $S D=10.89$ for batch 2010-2011). More importantly as discussed later, performance of the students between these two batches differed significantly $(p<0.05)$ where the marks obtained by them in non-case based items in the second semester examination was considered $(M=56.35, S D=9.85$ for batch 2009-10 versus $M=63.57, S D=7.79$ for batch 2010-2011).

Table 1: The Mean and Standard Deviation of the \% Marks Obtained by students of Batch 2009-2010 and Batch2010-2011

\begin{tabular}{|c|c|c|c|c|}
\hline Batch & Examination & $\mathbf{N}$ & $\begin{array}{c}\text { Mean of \% } \\
\text { Marks Obtained }\end{array}$ & $\begin{array}{l}\text { Standard } \\
\text { Deviation }\end{array}$ \\
\hline \multirow{3}{*}{ Batch 2009-2010 } & First Semester & 150 & 60.06 & 12.70 \\
\hline & $\begin{array}{l}\text { Second Semester } \\
\text { Case Based Items }\end{array}$ & 150 & 47.77 & 10.07 \\
\hline & $\begin{array}{l}\text { Second Semester } \\
\text { Non Case Based Items }\end{array}$ & 150 & 56.35 & 9.85 \\
\hline \multirow{3}{*}{ Batch 2010-2011 } & First Semester & 150 & 61.64 & 9.86 \\
\hline & $\begin{array}{l}\text { Second Semester } \\
\text { Case Based Items }\end{array}$ & 150 & 60.35 & 10.89 \\
\hline & $\begin{array}{l}\text { Second Semester } \\
\text { Non Case Based Items }\end{array}$ & 150 & 63.57 & 7.79 \\
\hline
\end{tabular}


Table 2: Results of Paired Sample Test for comparison of significance of difference of Mean \% Marks Obtained in First Semester, Case Based Items of Second Semester and Non Case Based Items of Second Semester between students of the Batch 2009-10 and Batch 2010-11

\begin{tabular}{|c|c|c|c|c|c|c|c|c|}
\hline & \multicolumn{5}{|c|}{ Paired Differences } & \multirow{3}{*}{$\mathbf{t}$} & \multirow{3}{*}{ df } & \multirow{3}{*}{$\begin{array}{c}\text { Significance } \\
\text { (2-tailed) }\end{array}$} \\
\hline & \multirow[t]{2}{*}{ Mean } & \multirow[t]{2}{*}{$\begin{array}{l}\text { Stdandard } \\
\text { Deviation }\end{array}$} & \multirow{2}{*}{$\begin{array}{l}\text { Standard } \\
\text { Error of } \\
\text { Mean }\end{array}$} & \multicolumn{2}{|c|}{$\begin{array}{l}\text { 95\% Confidence } \\
\text { Interval of Difference }\end{array}$} & & & \\
\hline & & & & Lower & Upper & & & \\
\hline \multicolumn{9}{|l|}{$\begin{array}{l}\text { First Semester } \\
\text { Batch 2009-10 }\end{array}$} \\
\hline Versus & & 16.62 & 1.36 & -4.26 & 1.10 & -1.16 & 149 & 0.246 \\
\hline \multicolumn{9}{|l|}{$\begin{array}{l}\text { First Semester } \\
\text { Batch 2010-11 }\end{array}$} \\
\hline \multicolumn{9}{|l|}{$\begin{array}{l}\text { Second Semester } \\
\text { Case Based Items } \\
\text { Batch 2009-10 }\end{array}$} \\
\hline Versus & -12.58 & 8.47 & 6913 & -13.95 & -11.21 & -18.20 & 149 & .000 \\
\hline \multicolumn{9}{|l|}{$\begin{array}{l}\text { Second Semester } \\
\text { Case Based Items } \\
\text { Batch } 2010-11\end{array}$} \\
\hline \multicolumn{9}{|l|}{$\begin{array}{l}\text { Second Semester } \\
\text { Non Case Based } \\
\text { Items Batch 2009-10 }\end{array}$} \\
\hline Versus & -7.22 & 13.21 & 1.08 & -9.35 & -5.09 & -6.69 & 149 & .000 \\
\hline $\begin{array}{l}\text { Second Semester } \\
\text { Non Case Based } \\
\text { Items Batch 2010-11 }\end{array}$ & & & & & & & & \\
\hline
\end{tabular}

\section{Discussion}

Evaluation of clinical conditions and management of health problems with competency, versatility and professional attitude require significant critical thinking (Abraham, 2000).

Secondly, it is an accepted fact that medical students must use critical thinking skills to relate concept to real-life situations. In the process of becoming an expert clinician, medical undergraduates acquire knowledge not only through listening to lectures and reading recommended textbooks but also solving scientific problems (Hmelo, 1998). Several researches have proven that along with other teaching methods, clinical case based learning creates an active learning environment (Smith, 1999).

In this light, the present study was undertaken to assess the efficacy of case based learning as an adjunct to traditional T-L methods in physiology. A comparison of mean marks obtained in the first semester examination between batch 2009-2010 and batch 20102011 showed that there was no significant difference in performance of the students between these two batches $(p=0.246)$. Thus, it may be established that students differed only insignificantly in their primary intellectual qualities. However, a significant difference was observed between the performances of the students of these two batches with regard to mean of marks obtained in case based items in the second semester examination ( $p<$ 0.05 ). This may be evident as no case based modules were discussed for batch 2009-2010 as was done for batch 2010-2011. As case based items required a higher level of cognitive skill frequently involved data interpretation and problem solving, development of such skill in students may require specialized training in those areas. In fact, no single teaching method has been described which has been observed to adequately ensure growth of critical thinking as well as clinical reasoning skill for students. However, incorporation of clinical case histories in tutorial classes along with other modes of existing T-L methods like didactic lectures, as was done for batch 2010-2011 during the second semester may be considered to be important in respect of:

- improvement in independent self-study involving problem solving and decision analysis in undergraduate medical students, 
- provision of a way to increase the exposure of students to clinical cases involving diagnostic and treatment procedures, that mimic real world scenarios, but with fewer resource implications,

- encouragement to realize the importance of physiology in medicine.

It was observed that the performance of students between these two batches differed significantly when the marks obtained by them in non-case based items in the second semester examination was $(p<0.05)$. Both batches being trained adequately in traditional T-L methods which should have sufficed to nullify any differences in the performance. This may be attributed to the case based modules introduced in T-L process to batch 2010-2011 but not to their earlier peers. Thus, an interesting finding of the present study emerged that clinical case based modules not only served to enhance students' skill in tackling case based items, but also developed their critical thinking and higher ordered learning such that they became more adept at solving non case based items. Thus, it may be reasonably inferred from the present study that clinical history based study is an important educational approach which aims to promote student-centered active learning with focus on questioning, critical thinking and problem solving. However, there is actually no necessity to derive a final solution to the problem. It is the process of learning how to learn which is more important. This teaching pattern is designed to stimulate learning process (Leggat, 2000). In context of the medical profession, Greenhalgh and (Hurwitz, have observed that narrative case studies provide meaning, context, and perspective for understanding the patient and can infuse the practice with "empathy, reflection, professionalism, and trustworthiness" (Bizzocchi, 2009; Greenhalgh, 1999).

Evaluation methods also need to be modified accordingly. Most of the present systems of evaluation demand a recall of the subject matter (Van Der Vleuten, 2000). Without clinical reasoning only the recall of factual data from memory has been described not to affect long term retention (Trottier, 1999). Therefore, effective teachers facilitate students' critical thinking and skill development when they implement learning activities that have authentic, real world context and personal relevance to students (Andrews, 1996).

\section{Conclusion}

In the present study, it was observed that incorporation of clinical case history based study along with regular lecture topics during the first year of MBBS study may have served to promote student-centered active learning with focus on questioning, critical thinking and problem solving. A significant observation of the present study was that clinical case based modules not only served to enhance students' skill in tackling case based items, but also developed their critical thinking and higher ordered learning such that they became more adept at solving non case based items.

\section{References}

Abraham, R.R., Upadhya, S., Torke, S. \& Ramnarayan, K. (2002) Clinically oriented physiology teaching: strategy for developing critical-thinking skills in undergraduate medical students, Advan Physiol Educ, 26, pp. 210-221.

Ananthakrishnan, N., Sethuraman, K.R. \& Kumar, S. (eds.) (2000). Medical Education: Principles and Practice $\left(2^{\text {nd }}\right.$ ed.) Pondicherry. Alumni Association of National Teacher's Training Centre, JIPMER.

Andrews, J. (1996) The teaching and learning transaction in higher education: a study of excellent professors and their students, Teaching in Higher Education, 1, pp. 81-103.

Asratyan, E.A. (2001) I. P. Pavlov: His life and work. The Minerva Group, pp. 14.

Bizzocchi, J.\& Schell, R. (2009) Rich-Narrative Case Study for Online PBL in Medical Education, Acad Med, 84, pp. 1412-1418.

Garrison D.R. (1992) Critical thinking and selfdirected learning in adult education. An analysis of responsibility and control issues, Adult Educ Quarterly 42, pp.136-148.

Greenhalgh, T. \& Hurwitz, B. (1999) Narrative based medicine: Why study narrative? BMJ, 318 , pp. $48-50$.

Hmelo, C.E. (1998) Problem-based learning: Effects on the early acquisition of cognitive skill in medicine. Journal of the Learning Science, 7, pp.173-208.

Leggat, P.A. (2000) Learning experiences in medical education. Med Teacher, 22, pp. 288292.

Medical Council of India. (1997) Regulations on graduate medical education 1997. New Delhi, India. (Amended up to November 2010) published in Part III, Section 4 of the Gazette of India dated 17th May 1997.

Murphy, K. \& Davidshofer, C. (2005) Psychological testing: Principles and applications (6th Ed). Upper Sadddle River, NJ: Prentice Hall. 
Patel, V.L., Evans, D.A \& Groen, G.J. (1989) Biomedical knowledge and clinical reasoning, Cognitive Science in Medicine: Biomedical Modeling Edited by: Evans DA, Patel VL. Cambridge, MIT Press, pp. 53-112.

Patel, V.L., Groen, G.J. \& Scott H.M. (1988) Biomedical knowledge in explanations of clinical problems by medical students, Med Educ, 22, pp. 398-406.

Scheme for First Professional MBBS University Examination in Physiology of the West Bengal University of Health Sciences [Online]. Available at http://www.thewbuhs.org.
Smith, S.R and Dollase, R. AMME Guide No: 14 (1999) Outcome based education: part 2planning, implementing and evaluating a competency based curriculum, Med Teacher, 21, pp. 15-22.

Trottier, R.W. (1999) A peer assisted learning system (PALS) approach to learning basic sciences. A model developed in basic medical pharmacology instruction, Med Teacher, 21, pp. 43-47.

Van Der Vleuten, C.P.M., Dolmans, D.H.J.M. and Scherpbier, X. (2000) The need for evidence in education, Med Teacher, 22, pp. 246-250. 